\title{
Effect of adenovirus-mediated uPA gene transduction on the fibrinolytic activity of human umbilical vein endothelial cells
}

\author{
WEIMIN ZHOU
}

\author{
Department of Vascular Surgery, The Second Affiliated Hospital of Nanchang University, \\ Nanchang, Jiangxi 330006, P.R. China
}

Received October 12, 2013; Accepted April 25, 2014

DOI: $10.3892 / \mathrm{mmr} .2014 .2518$

\begin{abstract}
The present study aimed to investigate the effect of adenovirus-mediated urokinase-type plasminogen activator (uPA) transduction on uPA expression and fibrinolytic activity in human umbilical vein endothelial cells (HUVECs). Recombinant adenovirus vectors containing the human uPA gene were constructed and transduced into HUVECs. The expression and fibrinolytic activity of uPA was then assessed in HUVECs using western blot analysis, ELISA and colorimetric assay. The experiments were performed in three groups: The $\mathrm{ad} / \mathrm{uPa}(\mathrm{n}=3), \mathrm{ad} / \mathrm{neg}$ control $(\mathrm{n}=3)$ and blank control $(\mathrm{n}=3)$ groups. Western blot analysis revealed that uPA protein expression in the HUVECs in the ad/uPa group was significantly increased compared with those in the ad/neg control or blank groups $(\mathrm{P}<0.01)$. The uPA protein levels in the supernatant of the three groups were $379.40 \pm 2.46,240.01 \pm 1.16$ and $256.10 \pm 3.04 \mathrm{ng} / \mathrm{l}$, respectively, showing that the uPA protein levels were significantly higher in the supernatant in the ad/uPa group compared with those in the ad/neg control or blank groups. uPA activity was determined using a colorimetric method and was found to be $40238.49 \pm 5755 \mathrm{IU} / \mathrm{mg}$ in the HUVECs in the $\mathrm{ad} / \mathrm{uPa}$ group, which was significantly higher than that in the HUVECs in the ad/neg control $(6180.03 \pm 942.38 \mathrm{IU} / \mathrm{mg})$ or blank groups $(3346.06 \pm 928.81 \mathrm{IU} / \mathrm{mg})$ (both $\mathrm{P}<0.01)$. These findings suggested that transduction of the uPA gene increased uPA protein expression and fibrinolytic activity in HUVECs.
\end{abstract}

\section{Introduction}

Deep vein thrombosis (DVT) is a serious disease, which is prone to progress to post-thrombotic syndrome (PTS), phlegmasia cerulea dolens, phlegmasia alba dolens and pulmonary embolism (PE), which may lead to mortality if not treated

Correspondence to: Dr Weimin Zhou, Department of Vascular Surgery, The Second Affiliated Hospital of Nanchang University, No. 1 Minde Road, Nanchang, Jiangxi 330006, P.R. China E-mail: weiminzhoucn@163.com; juanlicn@126.com

Key words: adenovirus vector, urokinase-type plasminogen activator, gene therapy, human umbilical vein endothelial cells properly. Retrospective studies have shown that patients with venous thromboembolism exhibit a high mortality rate between 5 and $23 \%$ worldwide (1), which remains between 1 and $2 \%$ even with anticoagulant treatment (2). It has been reported that one third of patients with DVT develop PTS (3) and 4-5\% of patients with PE develop pulmonary hypertension (4). DVT treatment is a clinical problem; however, urokinase is a venous thrombolytic drug that is commonly used in the clinical treatment of DVT. Urokinase-type plasminogen activator (uPA) is a second-generation fibrin-selective thrombolytic agent which is associated with a lower risk of bleeding than urokinase due to its high selectivity to fibrin (5-8). Adenovirus vectors are associated with a high efficiency of gene transfer and protein expression in a variety of cell types and are used in gene vaccines, gene therapy, tissue engineering and other studies, and are becoming one of the most widely used viral vectors. In the present study, the $\mathrm{pAD} / \mathrm{CMV} / \mathrm{V} 5-\mathrm{DEST}{ }^{\mathrm{TM}}$ Gateway $^{\circledR}$ vector was used for the construction of the adenovirus-uPA vector. The vector was then transduced into human umbilical vein endothelial cells (HUVECs) to investigate the effect of exogenous uPA on uPA expression and fibrinolytic activity in HUVECs.

\section{Materials and methods}

uPA gene synthesis. In accordance with the sequencing results of the complete uPA gene sequence, single-strand oligos were designed and synthesized. The oligos were then spliced into a complete gene using reverse-transcription polymerase chain reaction (RT-PCR) and inserted into the pMD-18T vector (Takara Bio, Inc., Shiga, Japan) for transformation into the competent DH5 $\alpha$ cells. The gene sequences in the recombinant clones were identified using DNA sequencing. Mutations in the gene sequences were repaired using overlapping PCR.

Construction of recombinant adenovirus vectors. Construction of recombinant adenovirus vectors was performed using the Gateway ${ }^{\circledR}$ Recombination Cloning system (Invitrogen Life Technologies, St. Louis, MO, USA) in a two-step process. The RT-PCR products of the complete uPA gene sequence were isolated and purified from the gel and digested using XhoI and SalI endonucleases to prepare the sequences for insertion into the pIRES2-EGFP vector (Takara Bio, Inc.) and the subsequent transformation into competent DH $5 \alpha$ cells. Gene sequencing was used to verify the recombinant plasmid. The plasmid containing 
Table I. Relative uPA mRNA expression in the human umbilical vein endothelial cells in the three groups ( $\mathrm{n}=3$ ).

\begin{tabular}{|c|c|c|c|c|c|}
\hline Group & $\mathrm{Ct}$ (target gene) & $\mathrm{Ct}$ (actin) & $\Delta \mathrm{Ct}$ & $\Delta \Delta \mathrm{Ct}$ & $2^{-\Delta \Delta C \mathrm{t}}$ \\
\hline Control & $25.31 \pm 0.10$ & $19.86 \pm 0.16$ & 5.45 & 0 & 1 \\
\hline $\mathrm{ad} / \mathrm{neg}$ & $14.57 \pm 0.11$ & $11.31 \pm 0.29$ & 3.26 & -2.19 & 4.5631 \\
\hline $\mathrm{ad} / \mathrm{uPA}$ & $27.55 \pm 0.14$ & $26.03 \pm 0.53$ & 1.52 & -3.93 & $15.2422^{\mathrm{a}}$ \\
\hline
\end{tabular}

${ }^{a} \mathrm{P}<0.01$ vs. the ad/neg and control groups. Ct, threshold cycle; uPA, urokinase-type plasminogen activator; neg, negative control; ad, adenovirus.

the gene sequences was puPA-IRES2-EGFP. It was then used as a template to amplify a uPA-IRES2-EGFP fragment containing restriction sites for $a t t \mathrm{~B} 1$ and $a t t \mathrm{~B} 2$. The following gene-specific primers were used: Forward, 5'-GGG GAC AAG TTT GTA CAA AAA AGC AGG CTT CGC CAC CAT GAG AGC CCT GC-3' and reverse, 5'-GGG GAC CAC TTT GTA CAA GAA AGC TGG GTC TTA CTT GTA CAG CTC GTC CAT GC-3'. The PCR product size was 2,600 bp.

The gene of interest was cloned into the entry vector pDONR221 using BP Clonase ${ }^{\mathrm{TM}}$ (Invitrogen Life Technologies). To produce the expression clone, the gene of interest from pDONR221 was subcloned into a destination vector $\mathrm{pAD} / \mathrm{CMV} / \mathrm{V} 5-\mathrm{DEST}$ containing the sequence information necessary for expression using the LR Reaction (Invitrogen Life Technologies). The recombinant plasmid was then verified by gene sequencing using the $\mathrm{nr}$ database and blastn program (http://www.ncbi.nlm.nih.gov; version 2.2.10). Comparision and analysis of the detected sequences were then performed.

Preparation and purification of the adenovirus and determination of the viral titer. The recombinant plasmid was digested using the PacI endonuclease and purified using a phenol-chloroform extraction method. The purity and concentration of the purified digestion product was determined using an ultraviolet spectrophotometer prior to being transduced into HUVECs (Shanghai Fuchun Zhongnan Biotechnology Co., Ltd., Shanghai, China) using Lipofectamine ${ }^{\circledR} 2000$ (Invitrogen Life Technologies) according to the manufacturer's instructions. The adenovirus was released from the cells using repeated freeze-thawing and collected by centrifugation. The viral solution was amplified primarily and the viral titer was assessed using immunization.

Determination of the optimal multiplicity of infection (MOI). Subsequent to adenovirus transduction, HUVECs were observed every $24 \mathrm{~h}$ and images were captured. The MOI that caused the highest transduction efficiency and the least cell damage was used for HUVEC transduction in the subsequent experiments. At $72 \mathrm{~h}$ after transduction, HUVECs were harvested for quantitative (q)PCR and western blot analyses. RNA was extracted by the TRIzol method (Invitrogen Life Technologies).

$q P C R$ analysis. The qPCR reaction conditions were as follows: $95^{\circ} \mathrm{C}$ for $2 \mathrm{~min}$ followed by 40 cycles of $95^{\circ} \mathrm{C}$ for $10 \mathrm{sec}, 60^{\circ} \mathrm{C}$ for $20 \mathrm{sec}$ and $72^{\circ} \mathrm{C}$ for $30 \mathrm{sec}$ then $72^{\circ} \mathrm{C}$ for $10 \mathrm{~min}$ and 70 cycles beginning at $60^{\circ} \mathrm{C}$ and increasing by $0.5^{\circ} \mathrm{C}$ every $30 \mathrm{sec}$, following which the temperature was increased to $95^{\circ} \mathrm{C}$.
uPA mRNA expression was detected using qPCR analysis. Relative quantification was calculated using the $2^{-\Delta \Delta \mathrm{Ct}}$ method $\left[\Delta \Delta \mathrm{Ct}=\left(\mathrm{Ct}_{\text {Target }}-\mathrm{Ct}_{\text {Actin }}\right)_{\text {Test }}-\left(\mathrm{Ct}_{\text {Target }}-\mathrm{Ct}_{\text {Actin }}\right)_{\text {Calibrator }}\right]$. $\beta$-actin was used as an internal control. 1-2- $-\Delta \Delta \mathrm{Ct}$ was considered to be the silencing efficiency of the target gene. The gene-specific uPA primer pair was as follows: Forward, 5'-CTA CTA CGG CTC TGA AGT CAC CAC-3' and reverse, 5'-GTA GAC GCC TGG CTT GTC CT-3'.

Detection of uPA protein expression. Cells were harvested and uPA protein expression was detected using western blot analysis (9). The supernatant of each group was collected to determine uPA concentration using ELISA.

Detection of uPA activity using colorimetric assay. The supernatants from the three HUVEC groups were immediately placed into the microplate reader in order to detect uPA activity using the spectrophotometer.

Statistical analysis. All data are presented as the mean \pm standard deviation and were analyzed using SAS v8.0 software (Statistical Analysis System Institute Inc., Cary, NC, USA). Comparisons between groups were performed using analysis of variance. $\mathrm{P}<0.05$ was considered to indicate a statistically significant difference.

\section{Results}

Identification of the adenovirus expression vector. The constructed expression vector was identified using DNA sequencing with an automatic sequencer (Fig. 1A and B). As verified using the basic local alignment search tool (http://blast.ncbi.nlm.nih.gov/Blast.cgi), the inserted sequence in the positive recombinant plasmid demonstrated complete homology to the human uPA cDNA sequence in the NCBI GenBank (https://www.ncbi.nlm.nih.gov/genbank/) (Fig. 2). The viral titer obtained was $5.74 \times 10^{10} \mathrm{ifu} / \mathrm{ml}$ following amplification. Thus, the adenovirus gene expression vector was constructed correctly and the virus was assembled successfully.

UPA mRNA expression in the transduced HUVECs. Following transduction with the adenovirus gene expression vector, HUVECs were harvested for UPA mRNA expression detection using qPCR analysis. The relative expression of uPA mRNA in the HUVECs in the ad/uPa group was significantly higher than that in the HUVECs in the ad/neg or control groups (both $\mathrm{P}<0.01$; Table I). 
A

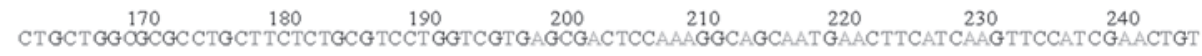

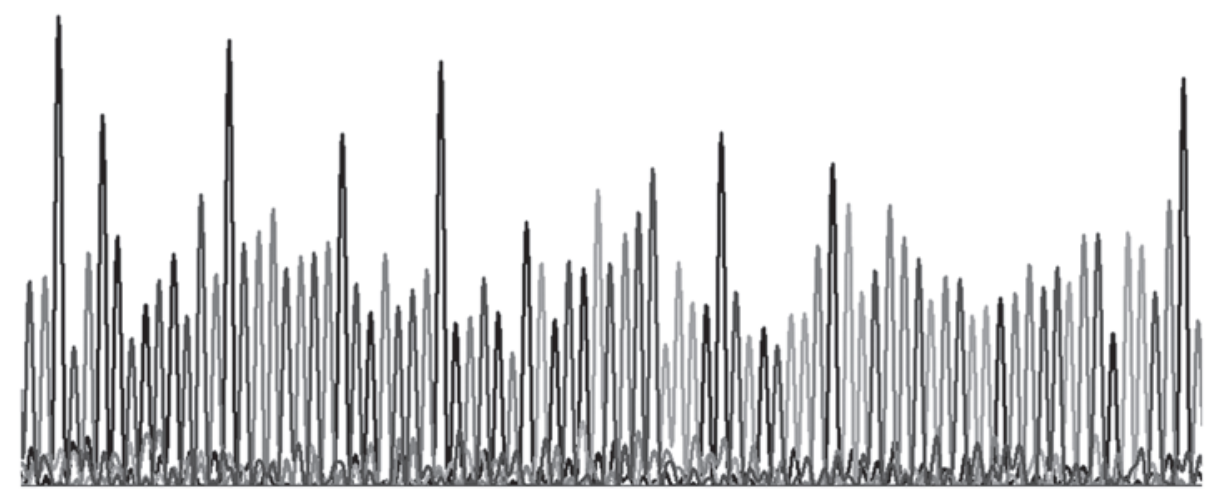

B

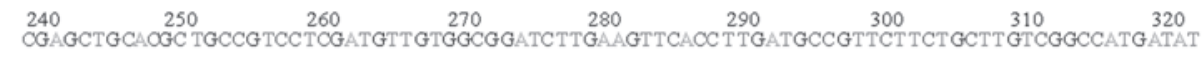

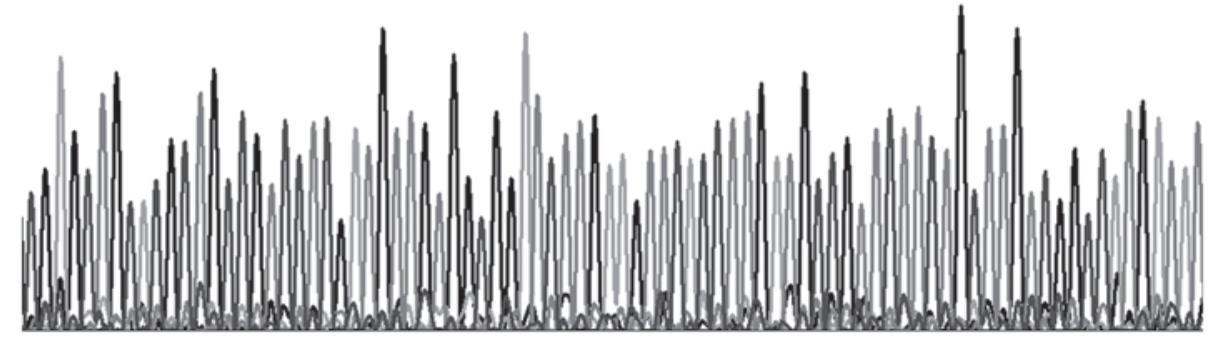

Figure 1. (A) Forward sequencing map of the inserted uPA fragment in the adenovirus recombinant plasmid. (B) Reverse sequencing map of the inserted uPA fragment in the adenovirus recombinant plasmid. uPA, urokinase-type plasminogen activator.

Distribution of 19 blast hits on the query sequence

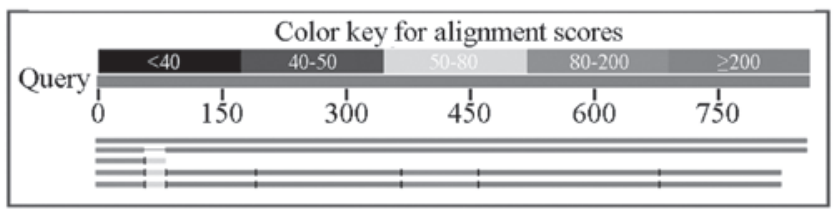

Figure 2. Overview of the BLAST result of the inserted fragment. BLAST, basic local alignment search tool.

uPA protein expression in the transduced HUVECs. uPA protein expression was analyzed in the HUVECs and the HUVEC supernatant following transduction with the adenovirus gene expression vector using western blot analysis (Fig. 3) and ELISA (Fig. 4), respectively. Anti-Myc antibodies were used to detect the expression of uPA as the UPA expression vector contained a Myc tag. Western blot analysis revealed that UPA expression in the HUVECs transfected with the adenovirus gene expression vector (MOI: 800) was significantly higher than that in the HUVECs transfected with negative vector or in the blank control HUVECs. The uPA concentration in the supernatant of the ad/uPa group was $379.40 \pm 2.46 \mathrm{ng} / \mathrm{l}$, which was significantly higher than that in the ad/neg $(240.01 \pm 1.16 \mathrm{ng} / \mathrm{l})$ or blank control (256.1024 $\pm 3.04 \mathrm{ng} / \mathrm{l})$ groups $(\mathrm{P}<0.01$; Fig. 4).

UPA activity in the transduced HUVECs. uPA activity in the HUVECs in the ad/uPa group (40238.49+5755 IU/mg) was found to be significantly increased compared with that in the HUVECs in the ad/neg $(6180.03 \pm 942.38 \mathrm{IU} / \mathrm{mg})$ or control (3346.06 $\pm 928.81 \mathrm{IU} / \mathrm{mg})$ groups $(\mathrm{P}<0.01$; Fig. 5).

\section{Discussion}

DVT is a common disease, which is harmful to patient health and quality of life. DVT has a poor clinical outcome and is prone to progress to PE and PTS and may result in limb loss and mortality. At present, the treatments for DVT primarily include anticoagulation, thrombolysis, surgical treatment or intervention therapy. However, to some extent, all of the above treatments are associated with bleeding, mortality, disability, thrombotic recurrence, as well as other disadvantages, which cause problems for DVT treatment. Thus, alternative treatment methods, including gene therapy, have attracted much research attention. Gene therapies for vascular diseases are still in experimental and subclinical stages (10-21). Appropriate genes and vectors are key to gene therapy and uPA and tissue plasminogen activator (tPA) are two thrombolytic agents, which have been proposed to have potential (14-18).

The human body has two plasminogen activators: uPA and tPA. uPA and tPA activate plasminogen into plasmin and thereby have a thrombolytic effect. uPA was originally purified from urine. Urogenital epithelial cells are the primary 


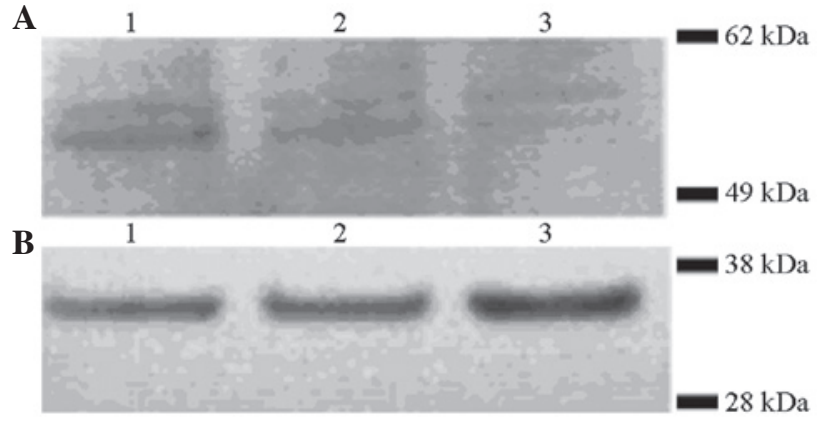

Figure 3. (A) UPA and (B) GAPDH protein expression in the human umbilical vein endothelial cells in the three groups detected using western blot analysis. Lane 1, ad/uPA group; lane 2, ad/neg group; and lane 3, control group. uPA, urokinase-type plasminogen activator; ad, adenovirus; neg, negative.

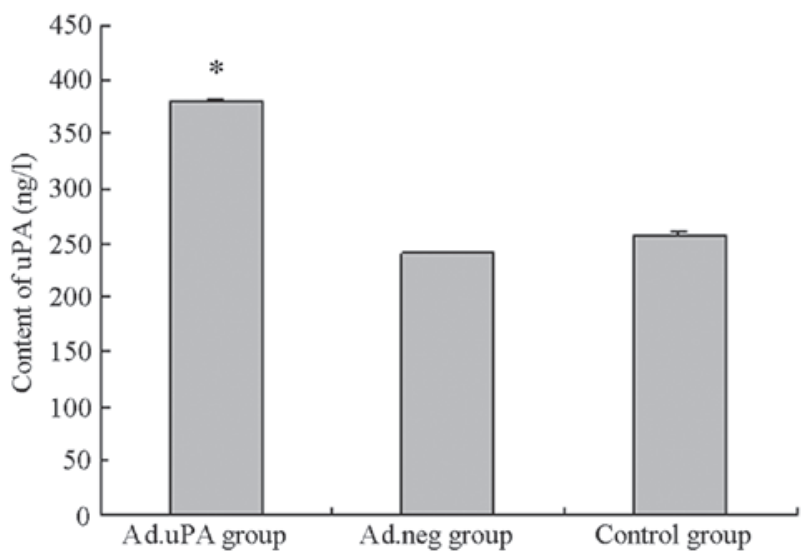

Figure 4. uPA concentration in the supernatant of the three groups of human umbilical vein endothelial cells measured using ELISA. uPA concentration in the ad/uPa group was significantly higher than that in the ad/neg or control groups. " $\mathrm{P}<0.01 \mathrm{vs}$. ad/neg and control groups. uPA, urokinase-type plasminogen activator; ad, adenovirus; neg, negative.

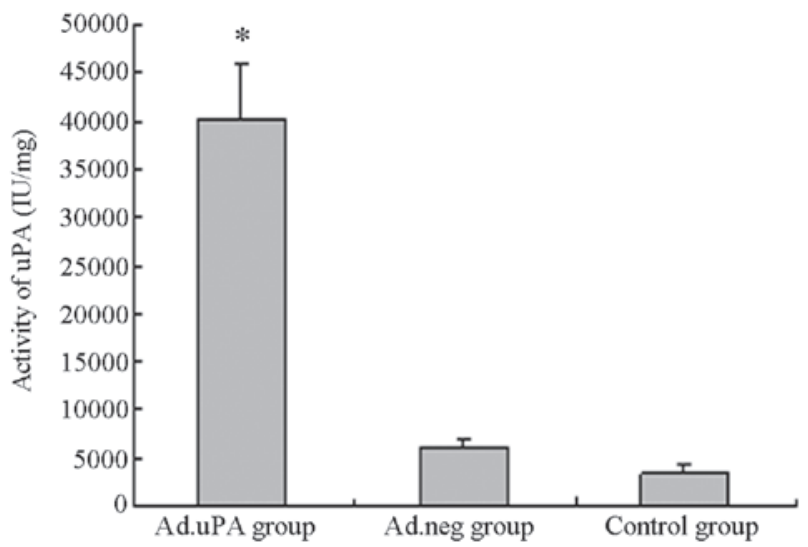

Figure 5. uPA activity in the human umbilical vein endothelial cells in the three groups detected using a colorimetric assay. uPA activity was significantly higher in the ad/uPA group than that in the ad/neg or control groups. ${ }^{*} \mathrm{P}<0.01 \mathrm{vs}$. ad/neg and control groups. uPA, urokinase-type plasminogen activator; ad, adenovirus; neg, negative.

producers of uPA, while uPA is not normally expressed in vascular endothelial cells (VECs). However, under culture conditions, uPA is expressed if VECs are stimulated with endotoxin or tumor necrosis factor (TNF) (22).
The human uPA gene is located on the long arm of chromosome 10, at 10q24. The uPA gene consists of 11 exons and 10 introns with a size of $6.4 \mathrm{~kb}$, which generates a mature mRNA of $2.4 \mathrm{~kb}$ and translates into pro-urokinase. uPA is a serine proteolytic enzyme containing 411 amino acid residues. It is a glycoprotein with a molecular weight of $50-60 \mathrm{kDa}$, constructed by two polypeptide chains bridged by a disulfide bond. uPA activates plasminogen directly without the cofactor fibrin.

Gene therapy involves introducing an exogenous gene into somatic cells using genetic engineering technology, making the cells express the corresponding protein in order to prevent or treat a disease. As a major component of the vascular wall, VECs are not only a natural barrier for the blood vessel wall, but also an important endocrine organ that synthesizes a variety of cytokines. Due to the location of VECs in the blood vessel wall, the proteins secreted by VECs not only act in local blood vessels, but also have a role in the systemic circulation. Thus, VECs are particularly important target cells (23).

In vivo, VECs only express tPA; however, VECs have been found to synthesize and secrete tPA and UPA in vitro. Interleukin-1, TNF $\alpha$, plasmin and $\alpha$-tocopherol have been reported to reduce the release of tPA from VECs. Plasminogen, UPA and tPA receptors are expressed on the surface of endothelial cells and promote the activation of plasminogen. Under pathological conditions, the levels of uPA in the human body are not sufficient to prevent and treat thrombosis. Therefore, introducing the exogenous uPA gene into mammalian endothelial cells in order to produce more uPA protein with higher biological activity is of great importance for the prevention and treatment of thrombosis.

qPCR is an assay which is used to analyze gene transcription. qPCR quantitatively analyzes mRNA levels, prior to colorimetric analysis, which saves time during clinical diagnosis and treatment, particularly for predicting changes in the fibrinolytic system $(24,25)$. In addition, qPCR has a real-time signal monitoring feature, which avoids the error caused by the 'platform effect'. In the present study, qPCR analysis was used to analyze uPA mRNA expression. During qPCR analysis, mRNA templates are quantitatively analyzed using the $\mathrm{Ct}$ method and standard curves are generated by analyzing the changes in the fluorescent signals in each cycle of the PCR reaction. The $\mathrm{Ct}$ value refers to the number of cycles required for the fluorescent signal in each reaction to reach the set threshold. The Ct value of each mRNA template has a linear negative correlation with its initial copy number. A standard curve is generated using a proof sample with known initial copy numbers. According to the standard curve, the initial copy numbers of the test samples can be calculated using their $\mathrm{Ct}$ values. The $2^{-\Delta \Delta \mathrm{Ct}}$ method is a convenient method used to calculate the relative changes in gene expression in $\mathrm{qPCR}$ analysis (26-30). qPCR analysis is more sensitive, simple and specific than traditional northern blot analysis. In the present study, uPA and an internal control were successfully amplified using qPCR analysis. The uPA sequences amplified spanned at least two exons in order to exclude the contamination of genomic DNA. The housekeeping gene $\beta$-actin was used as an internal control, which exhibits universal and constant expression in all tissues. Thus, it can be used to reduce the error during qPCR analysis or RNA quantitation. 
In the present study, HUVECs transduced with the uPA gene were observed to secrete more uPA protein than control HUVECs. UPA activity was also found to be significantly increased in the UPA-transduced HUVECs, indicating that the exogenous uPA gene is transcribed and the uPA protein is synthesized and secreted in HUVECs. An adenovirus containing the uPA gene was successfully transduced, generating HUVECs stably expressing uPA and providing a strong foundation for future research on direct or indirect uPA gene therapy in vivo. However, prior to being used in vivo, it must be verified that the uPA-adenovirus can be successfully transfected into HUVECs and has an influence on the biological characteristics of HUVECs. Whether such an exogenous gene has biological effects in vivo requires further investigation using animal experiments.

\section{References}

1. Goldhaber SZ: Pulmonary embolism. Lancet 363: 1295-1305, 2004.

2. Spencer FA, Emery C, Lessard D, et al: The Worcester Venous Thromboembolism Study: A population based study of the clinical epidemiology of venous thromboembolism. J Gen Intern Med 21: 722-727, 2006.

3. Chapman NH, Brighton T, Harris MF, Caplan GA, Braithwaite J and Chong BH: Venous thromboembolism - management in general practice. Aust Fam Physician 38: 36-40, 2009.

4. Pengo V, Lensing AW, Prins MH, et al; Thromboembolic Pulmonary Hypertension Study Group: Incidence of chronic thromboembolic pulmonary hypertension after pulmonary embolism. N Engl J Med 350: 2257-2264, 2004.

5. Vincenza Carriero M, Franco P, Vocca I, et al: Structure, function and antagonists of urokinase-type plasminogen activator. Front Biosci (Landmark Ed) 14: 3782-3794, 2009.

6. Radha KS, Madhyastha HK, Nakajima Y, Omura S and Maruyama M: Emodin upregulates urokinase plasminogen activator, plasminogen activator inhibitor-1 and promotes wound healing in human fibroblasts. Vascul Pharmacol 48: 184-190, 2008

7. Nassar T, Yarovoi S, Fanne RA, et al: Urokinase plasminogen activator regulates pulmonary arterial contractility and vascular permeability in mice. Am J Respir Cell Mol Biol 45: 1015-1021, 2011.

8. Baldwin JF, Sood V, Elfline MA, et al: The role of urokinase plasminogen activator and plasmin activator inhibitor-1 on vein wall remodeling in experimental deep vein thrombosis. J Vasc Surg 56: 1089-1097, 2012.

9. Rao Gogineni V, Kumar Nalla A, Gupta R et al: Radiationinducible silencing of UPA and UPAR in vitro and in vivo in meningioma. Int J Oncol 36: 809-816, 2010.

10. Ylä-Herttuala S: Cardiovascular gene therapy with vascular endothelial growth factors. Gene 525: 217-219, 2013.

11. Zhao B, Li X, Dai X and Gong N: Adenovirus-mediated anti-sense extracellular signal-regulated kinase 2 gene therapy inhibits activation of vascular smooth muscle cells and angiogenesis, and ameliorates transplant arteriosclerosis. Transplant Proc 45: 639-642, 2013.

12. Dragneva G, Korpisalo P and Ylä-Herttuala S: Promoting blood vessel growth in ischemic diseases: challenges in translating preclinical potential into clinical success. Dis Model Mech 6: 312-322, 2013
13. Kral BG and Kraitchman DL: From mice to men: gene therapy's future for treatment of myocardial infarction. Circ Cardiovasc Imaging 6: 360-362, 2013.

14. Botkjaer KA, Fogh S, Bekes EC, et al: Targeting the autolysis loop of urokinase-type plasminogen activator with conformation-specific monoclonal antibodies. Biochem J 438: 39-51, 2011.

15. Sood V, Luke CE, Deatrick KB, et al: Urokinase plasminogen activator independent early experimental thrombus resolution: MMP2 as an alternative mechanism. Thromb Haemost 104: 1174-1183, 2010.

16. Humphries J, Gossage JA, Modarai B, et al: Monocyte urokinase-type plasminogen activator up-regulation reduces thrombus size in a model of venous thrombosis. J Vasc Surg 50: 1127-1134, 2009.

17. Madhyastha R, Madhyastha H, Nakajima Y, Omura S and Maruyama M: Curcumin facilitates fibrinolysis and cellular migration during wound healing by modulating urokinase plasminogen activator expression. Pathophysiol Haemost Thromb 37: 59-66, 2010.

18. Shenkman B, Livnat T, Budnik I, Tamarin I, Einav Y and Martinowitz U: Plasma tissue-type plasminogen activator increases fibrinolytic activity of exogenous urokinase-type plasminogen activator. Blood Coagul Fibrinolysis 23: 729-733, 2012.

19. Lipskaia L, Hadri L, Lopez JJ, Hajjar RJ and Bobe R: Benefit of SERCA2a gene transfer to vascular endothelial and smooth muscle cells: a new aspect in therapy of cardiovascular diseases. Curr Vasc Pharmacol 11: 465-479, 2013

20. Hennessy EJ and Moore KJ: Using microRNA as an alternative treatment for hyperlipidemia and cardiovascular disease: cardio-miRs in the pipeline. J Cardiovasc Pharmacol 62: 247-254, 2013.

21. Won YW, McGinn AN, Lee M, Nam K, Bull DA and Kim SW: Post-translational regulation of a hypoxia-responsive VEGF plasmid for the treatment of myocardial ischemia. Biomaterials 34: 6229-6238, 2013.

22. Yamaguchi Y, Yamada K, Suzuki T, et al: Induction of uPA release in human peripheral blood lymphocytes by [deaminoCysl,D-Arg8]-vasopressin (dDAVP). Am J Physiol Endocrinol Metab 287: E970-E976, 2004.

23. De Meyer SF, Deckmyn H and Vanhoorelbeke K: von Willebrand factor to the rescue. Blood 113: 5049-5057, 2009.

24. Chey S, Claus C and Liebert UG: Validation and application of normalization factors for gene expression studies in rubella virus-infected cell lines with quantitative real-time PCR. J Cell Biochem 110: 118-128, 2010.

25. Gu Z, Pan J, Bankowski MJ and Hayden RT: Quantitative real-time polymerase chain reaction detection of BK virus using labeled primers. Arch Pathol Lab Med 134: 444-448, 2010.

26. Livak KJ and Schmittgen TD: Analysis of relative gene expression data using real-time quantitative PCR and the 2(-Delta Delta C(T)) Method. Methods 25: 402-408, 2001.

27. Oliveira MS, Skinner F, Arshadmansab MF, et al: Altered expression and function of small-conductance (SK) $\mathrm{Ca}(2+)$-activated $\mathrm{K}^{+}$channels in pilocarpine-treated epileptic rats. Brain Res 1348: 187-199, 2010.

28. Liang F, Arora N, Zhang KL, et al: A new, multiplex, quantitative real-time polymerase chain reaction system for nucleic Acid detection and quantification. Methods Mol Biol 1039: 51-68, 2013.

29. Wagner EM: Monitoring gene expression: quantitative real-time rt-PCR. Methods Mol Biol 1027: 19-45, 2013.

30. Gentilini F and Turba ME: Two novel real-time PCR methods for genotyping the von Willebrand disease type I mutation in Doberman Pinscher dogs. Vet J 197: 457-460, 2013. 